tions to authors (printed in full in the first issue of every year and latterly, abbreviated, in the News pages every week). We do not want to impose handling charges for every article and page changes for the accepted paper, because all these would do is deprive medicine of much needed funds for research. Nevertheless, eventually we and many other journals may be forced by economic considerations to decline to consider for publication any article that does not use the standard conventions.

1 British Medical fournal, 1977, 2, 1428.

Williams, P C, Units, Symbols, and Abbreviations, ed G Ellis, p 35. London Royal Society of Medicine, 1972.

Ner" England fournal of Medicine, 1970, 282, 48

1 IUB Commission of Editors of Biochemical Journals, Biochemical fournal, 1973, 135, 1 .

Garfield, E, Nezi Scientist, 1968, 39, 565

O'Connor, M, British Medical fournal, 1978, 1, 31.

Smith, J, British Medical fournal, 1978, 1, 222.

\section{Ebstein's anomaly}

Ebstein's anomaly of the tricuspid valve ${ }^{1}$ is one of the rarer congenital cardiac malformations. Attention has been called to it in two recent articles: one showed that the prognosis was generally good with conservative management, ${ }^{2}$ while the other showed the feasibility of surgical treatment. ${ }^{3}$

The basic anomaly is a downward displacement of the attachment of the base of the tricuspid valve from the true valve ring into the cavity of the right ventricle. The medial and inferior leaflets are those most frequently affected, but sometimes the whole valve is displaced. ${ }^{4}$ As a result of the displacement the right ventricle is divided by the tricuspid valve into a distal, effective ventricle and a proximal "atrialised" portion which is thin-walled and poorly contractile. While the thickness of the distal ventricle is usually normal in some instances it, too, is attenuated. The relative sizes of the cavities of the effective right ventricle and the atrialised portion depend on the degree of displacement of the valve, and this is extremely variable. ${ }^{4}$ The tricuspid valve usually shows additional abnormalities. The leaflets may be fused at their edges, sometimes leading to tricuspid stenosis, or they may be perforated and sometimes portions are entirely absent. ${ }^{6}$

Even in its simplest form Ebstein's anomaly is, then, of highly variable severity, depending on the degree of displacement and dysplasia of the valve and the size and function of the effective right ventricle. Even this is not the whole picture, since half the affected patients have additional cardiac abnormalities. The most common is atrial septal defect or patent foramen ovale. About $20^{\prime \prime}$ " have more serious abnormalities including ventricular septal defect, pulmonary stenosis or atresia, the tetralogy of Fallot, mitral stenosis, and corrected transposition of the great arteries. Finally there is a high incidence of cardiac arrhythmias, sometimes associated with Wolff-Parkinson-White type B pre-excitation.

The rarity of Ebstein's anomaly (less than 100 children per year in Britain) and the diversity of the lesions have made the assessment of its clinical course and natural history difficult. The presentation may be with an asymptomatic cardiac murmur, with an arrhythmia, with cyanosis due to a right to left shunt through an atrial septal defect or foramen ovale, or with congestive cardiac failure. The course of the disease depends on the severity of the basic tricuspid valve lesion and the presence or absence of associated cardiac abnormalities. ${ }^{78}$ Certain facts are evident. A poor prognosis is associated with presentation in the first year of life, almost half of such patients dying early. ${ }^{78}$ Once through this danger period the prospects for survival into adult life are good. ${ }^{2}$ Nevertheless, at any age the appearance of cyanosis indicates a poor prognosis, while the onset of congestive cardiac failure is a particularly grave sign, few patients surviving for more than a few years.

Fortunately, in older children and adults surgery is feasible. ${ }^{3}$ The procedure consists of tricuspid valve replacement, obliteration of the atrialised portion of the right ventricle, and closure of the patency of the atrial septum, if present. ${ }^{3} 9$ Surgical treatment is generally reserved for those patients with cyanosis or congestive cardiac failure, while asymptomatic patients are treated conservatively. This approach should maximise the chances of survival for adults and older children with Ebstein's anomaly; but the management of the highestrisk cases, the infants, remains an unsolved problem.

1 Ebstein, W, Archiv für Anatomie und Physiologie, 1866, 33, 238.

2 Fischer-Hansen, J, et al, Acta Medica Scandinavica, 1977, 201, 331.

${ }^{3}$ Jugdutt, B I, et al, fournal of Thoracic and Cardiovascular Surgery, 1977, 73, 20.

${ }^{4}$ Lev, M, et al, Archives of Pathology, 1970, 90, 334

${ }^{5}$ Genton, E, and Blount, S G, American Heart fournal, 1967, 73, 395.

6 Becker, A E, Becker, M J, and Edwards, J E, Archives of Pathology, 1971, $\mathbf{9 1}, 167$.

Kumar, E A, et al, American fournal of Cardiology, 1971, 28, 84

Watson, H, British Heart fournal, 1974, 36, 417.

${ }^{9}$ Hardy, K L, et al, fournal of Thoracic and Cardiovascular Surgery, 1964, 48,927 .

\section{Treatment of osteoporosis}

As long ago as 1941 Albright and his colleagues suggested that postmenopausal osteoporosis in women is caused by oestrogen deficiency. ${ }^{1}$ Other possible contributory factors are a small skeleton at maturity, ${ }^{2}$ the calcium malabsorption of old age ${ }^{3}$ and a high-protein diet. ${ }^{4}$ 5 Bone mass may not be the only factor which determines bone strength. Old bone is more fully calcified than young, and this may explain why less energy is required to fracture bones in adults than in children. ${ }^{6}$ Racial differences may also be important: among women aged over 70 in Johannesburg those who are white fracture their necks of femur at least 10 times as frequently as those who are black -in spite of their having no less bone mass as estimated by metacarpal radiogrammetry. ${ }^{7}$

Osteoporotic patients have about $20 \%$ less bone than their normal peers, ${ }^{8}$ whereas in both groups the annual rate of renewal of old bone is only about $5^{\circ}{ }_{0} \cdot{ }^{9-11}$ This means that even if bone breakdown could be arrested completely with formation continuing unabated at least four years' treatment would be needed for the average patient with osteoporosis to regain a bone mass normal for her age. Even this is unattainable because a substantial fraction of new bone formation occurs in the Haversian systems of cortical bone and is necessarily preceded by bone breakdown. Furthermore, many treatments proposed for osteoporosis, such as oestrogens, calcium supplements, and thiazide diuretics, reduce turnover and would thereby delay recovery further. ${ }^{12-14}$

The two fundamentally different approaches to treatment are prevention and restoration. Prevention aims at reducing bone resorption so that formation can keep pace. Hormone replacement, calcium supplements, and vitamin D (together 
with its analogues and metabolites) all fall into this group. The results of three prospective controlled trials have now appeared, in which treated subjects in their first menopausal decade were compared with matched controls. ${ }^{14-16}$ All found that treatment with oestrogens (with testosterone added in one trial $^{14}$ ) eliminated the measured $1-4 \%$ annual losses observed in the controls. Lindsay et $a l^{17}$ have since published the results of a small prospective study which suggest that progestogens may be as effective as oestrogens, whereas the Leeds $^{16}$ and Nebraska ${ }^{14}$ trials included groups treated with calcium supplements alone. These lost bone at rates intermediate between the controls and those receiving oestrogens.

Normally calcium absorption is inhibited by a high-calcium diet, but at least some of the extra dietary calcium must be absorbed. Indeed, in the Nebraska study urine calcium concentrations rose by a mean of $1 \mathrm{mmol}$ day. Older women, however, absorb calcium less effectively, ${ }^{3}$ and this has provided the rationale for giving vitamin $\mathrm{D}$ and its analogues. Pharmacological doses of vitamin $\mathrm{D}$ are often required to achieve a measurable effect in this age group, ${ }^{3}$ whereas when synthetic $1 \propto(\mathrm{OH}) \mathrm{D}_{3}$ is used (which the liver hydroxylates to the active metabolite $1,25(\mathrm{OH})_{2} \quad D_{3}$ ) doses of only 1 or $2 \mu \mathrm{g}$ per day are effective in raising calcium absorption. Unfortunately, hypercalcaemia may occur at these doses, ${ }^{1819}$ and much of the extra calcium absorbed finds its way into the urine.

Clearly, then, bone loss may be delayed or prevented by prophylactic use of oestrogens or calcium supplements. What are the risks of such treatment? In the case of oestrogens the principal risk is possibly endometrial carcinoma, although the size of the risk remains to be defined. ${ }^{20}$ The risk of taking calcium supplements is small; from Nordin's data ${ }^{21}$ the rise in urine calcium with calcium supplements could be predicted to lead to a $10-20^{\circ}$ increase in the (low) incidence of renal stones. Nevertheless, since both agents at their recommended doses reduce bone turnover, both would be expected to lead to a more completely calcified skeleton; and the relative gain in bone mass might yet prove to be at the expense of the quality of the bone.

The alternative approach is to attempt to restore the skeletal mass after decline has occurred. To achieve results within a reasonable time the first requirement is to stimulate bone formation. Three agents have shown promise: fluoride, growth hormone, and the human synthetic parathyroid hormone fragment hPTH (1-34). All three agents stimulate the formation of new bone-forming cells, and fluoride may additionally inhibit resorption. Initial experience with fluoride was disappointing, since the formation of excess osteoid was observed. ${ }^{12}$ Encouraging reports of studies in which vitamin $\mathrm{D}$ and calcium supplements were added ${ }^{12} 2223$ have since appeared, but further experience is awaited.

Growth hormone ${ }^{24}$ and hPTH $(1-34)^{25}$ both appreciably increased bone turnover, but the average calcium balance changed little. On general grounds hPTH (1-34) is preferable: at low doses it does not produce hypercalcaemia and it should be free from other side effects. Nevertheless, it remains to be seen whether the osteoclastic response to hPTH can be reduced by modifying the dose or by combining it with an antiosteoclastic agent.

Nothing has yet been shown to reverse involutional osteoporosis, while prophylactic oestrogens and calcium supplements must still be shown to reduce the fracture rate. Meanwhile we need to establish the size and characteristics of the group of individuals at risk so they may be identified before they develop fractures. If we find that patients have to be supervised closely, we shall then have to assess the practica- bility of large-scale prophylaxis in the light of future progress in treating established osteoporosis by agents stimulating bone formation. Clearly the research effort being expended on these questions is fully justified by the size of the problem: the SW Thames region alone continuously fills the equivalent of a 250-bedded hospital with patients with fractured neck $\cong$ of the femur ${ }^{26}$ and the annual cost of this single injury in Europe and North America in 1978 will exceed US $\$ 2000 \mathrm{~m}$. $\underset{\vec{\sigma}}{\vec{\theta}}$

${ }^{1}$ Albright, F, Smith, P H, and Richardson, A M, fournal of the American Medical Association, 1941, 116, 2465.

${ }^{2}$ Nilsson, B E, Clinical Orthopaedics and Related Research, 1970, 68, 93.

${ }^{3}$ Nordin, B E C, et al, Calcified Tissue Research, 1976, 21, suppl, 442.

4 Linkswiler, H M, Joyce, C L, and Anand, C R, Transactions of the Nez York Academy of Sciences, 1974, 36, 333.

5 Thompson, D L, and Frame, B, Annals of Internal Medicine, 1976, 85, 789. ?

Currey, J D, and Butler, G, Fournal of Bone and foint Surgery, 1975, 57A, 810

7 Solomon, L, Lancet, 1978, in press.

${ }^{8}$ Cohn, S H, et al, fournal of Nuclear Medicine, 1974, 15, 428.

${ }^{9}$ Marshall, J H, et al, Health Physics, 1973, 24, 125.

10 Reeve, J, Hesp, R, and Wootton, R, Calcified Tissue Research, 1977,

22, suppl, 311.
${ }_{11}$ Meunier, P, et al, Clinics in Endocrinology and Metabolism, 1973, 2, 239.

12 Riggs, B L, et al, Clinics in Endocrinology and Metabolism, 1973, 2, 317.

${ }^{13}$ Harrison, J E, et al, Metabolism, 1971, 20, 1107.

${ }^{14}$ Recker, R R, Saville, P D, and Heaney, R P, Annals of Internal Medicine, $1977,87,649$.

${ }^{15}$ Lindsay, R, et al, Lancet, 1976, 1, 1038

${ }^{16}$ Horsman, A, et al, British Medical fournal, 1977, 2, 789.

Marshall, D H, and Nordin, B E C Clinical Endocinoline, 1978, 54, 193. N

19 Sorensen, O H, et al, Clinical Endocrinology, 1977, 7, 169S.

${ }^{20}$ Doll, R, et al, Lancet, 1977, 1, 745.

${ }_{21}$ Nordin, B E C, Clinical Science and Molecular Medicine, 1977, 52, 1.

22 Parsons, V, et al, Calcified Tissue Research, 1977, 22, suppl, 236.

${ }^{23}$ Meunier, P J, et al, presented to the 2nd CEMO Symposium "Fluoride and Bone", Nyon, Switzerland, October 1977.

${ }^{24}$ Haas, H G, et al, Calcified Tissue Research, 1976, 21, suppl, 467.

${ }_{25}$ Reeve, J, et al, in Proceedings of the 6th Parathyroid Conference, eds D $\mathrm{H}$ Copp and R V Talmage, p 71. Amsterdam, Excerpta Medica, 1978.

${ }^{26}$ Gallannaugh, S C, Martin, A, and Millard, P H, British Medical fournal, $1976,2,1496$

\section{Varicocele and subfertility}

In 1550 Ambroise Paré aptly described varicocele as "a compact pack of vessels quite filled with melancholic blood." $\delta$ Over the years the condition attracted scant attention: it was attributed to inadequate sexual relief, and late marriage was 온 considered a strong predisposing factor. In 1889 Bennett $^{1} \stackrel{\sim}{\sim}$ described a technique for its radical cure and commented "in $\frac{D}{0}$ many cases secretion of spermatozoa is arrested." Nevertheless, little notice was taken of the possible deleterious effects $\tilde{N}$ of a varicocele on fertility until 1952, when Tulloch ${ }^{2}$ reported $\underset{\omega}{N}$ the return of normal spermatogenesis after ligation of the lesion in an azoospermic man, who subsequently fathered a child. Three years later he reported the results of treatment in 30 subfertile men who had had ligation of varicocele, five bilaterally: 20 showed a significant improvement in the sperm count and 10 became fathers. Numerous reports ${ }^{4-9}$ since then $\stackrel{\mathbb{D}}{?}$ have confirmed that the sperm count will improve after $\stackrel{\mathbb{D}}{\mathbb{Q}}$ operation in about two-thirds of these patients.

Varicocele is common: Johnson and colleagues ${ }^{10}$ found 151 among 1592 normal US Air Force recruits aged between 17 응 and $24 ; 94$ of these men produced semen samples, of which $56^{\circ}$ o showed reduced motility and $27^{\circ}$ o low sperm counts. Varicocele is much more common among men attending subfertility clinics, where the reported incidence varies between $19^{11}$ and $39^{\circ}{ }_{0} .^{12}$ Retrograde caval venography ${ }^{13}{ }^{14}$ has 